\title{
Google Earth Engine for concurrent flood monitoring in the lower basin of Indo-Gangetic-Brahmaputra plains
}

\author{
Preet Lal $^{1}$ (D) $\cdot$ Aniket Prakash $^{1}$ (D) $\cdot$ Amit Kumar $^{1}$ (D)
}

Received: 2 August 2020 / Accepted: 14 August 2020 / Published online: 24 August 2020

(c) Springer Nature B.V. 2020

\begin{abstract}
The present study focused on the recent flood inundation (July 2020) that occurred in the lower Indo-Gangetic-Brahmaputra plains (IGBP) using concurrent C-band Sentinel-1A Synthetic Aperture Radar images in Google Earth Engine. The study exhibited that a substantial proportion of IGBP $\left(40,929 \mathrm{~km}^{2}\right)$ was inundated primarily in Bangladesh $(9.09 \%$ of the total inundation), Assam (8.99\%), and Bihar (6.29\%) during June-July 2020. The severe impact of flood inundation was observed in croplands ( $4.41 \%$ of the total cropland), followed by settlements (20.98\% of the total settlements) that affected a large population $(\sim 10,046,262)$ in IGBP. The prevailing COVID-19 pandemic has debilitated the efforts of mitigation and responses to flooding risks. The study necessitates adopting an integrated, multi-hazard, multi-stakeholder approach with an emphasis on self-reliance of the community for sustenance with local resources and practices.
\end{abstract}

Keywords Sentinel 1A $\cdot$ SAR $\cdot$ Flood hazard $\cdot$ Risk

\section{Background}

Recurrent flooding in the Indian sub-continent has prevalent phenomena in the last few years due to the increased frequency of high erratic and anomalous precipitation (Tanoue et al. 2016). It has devastating effects in Indo-Gangetic-Brahmaputra plains (IGBP) due to the increased severity in terms of loss of lives and property (Kale 2003). The Ganges, Brahmaputra, and Meghna rivers in the lower basin of IGBP bring an enormous volume of water that leads to recurrent flooding approximately every year (Mohanty et al. 2020). The higher melting of glaciers in the central and the eastern Himalayan region, coupled with a sudden decrease in river bed slope, and the torrential precipitation during the Indian summer monsoon, intensify the run-off in the downstream and causes annual flooding (Dimri

Amit Kumar

amit.iirs@gmail.com; amit.kumar@cuj.ac.in

Preet Lal

preetlal2011@gmail.com

Aniket Prakash

aniketprakash95@gmail.com

1 Department of Geoinformatics, Central University of Jharkhand, Ranchi 835205, India 
and Allen 2020). The land-use alterations, increased soil erosion, increased siltation in the river, and growth of human settlements in low-lying areas augmented the flood severity many folds (Mullan et al. 2019). It has been reported that floods in India caused damage to over a billion US\$ from 1993 to 2018 (Nagar 2018), due to high climatic extremes coupled with increased anthropogenic influences (Milly et al. 2002). In 2020, several districts (149 in India and 64 in Bangladesh) in the lower basin of IGBP (including Bihar, Assam, West Bengal in India, and in entire Bangladesh) were on high alert due to a rise in the level of water above the danger mark simultaneously with heavy and incessant rains (CWC 2020). Later, the region observed the devastating effects of the flood amid the COVID-19 period. Therefore, in the present study, the spatial extent of flood inundation in the lower basin of IGBP was mapped, and later, its impact on land use/land cover (LULC) and population were analyzed.

\section{Materials and method}

Google Earth Engine (GEE) cloud platform was used to execute multiple tasks impeccably from concurrent SAR satellite data retrieval for flood mapping, and to deduce its impact on LULC, and population on a parallel processing architecture. The Sentinel-1A VH polarization images were retrieved during the pre-flood period (15 May to 15 June 2020) and the peak flood period (30 June to 18 July 2020). The various pre-processing techniques, including orbit correction, radiometric calibration, removal of noise, orthorectification, and conversion of sigma to decibels, were performed. The peak flood mosaic was divided by the pre-flood mosaic to deduce the change per pixel. The threshold of 1.25 was applied to deduce flood hazard in the lower basin of the IGBP. The JRC Global Surface Water dataset $(2018 ; 30 \mathrm{~m}$ resolution) was used to mask the areas covered by water for $>10$ months year ${ }^{-1}$. The population density (person pixel $^{-1} ; 250 \mathrm{~m}$ resolution) was acquired from JRC Global Human Settlement Population Layer (GHSL; 2015) and used to estimate the number of marooned populations by overlaying the flood inundation layer. The MODIS Land Cover Type product (500 m resolution) was reclassified and used to deduce the impact of flood inundation on different LULC especially on cropland, and settlements.

\section{Results and discussion}

The C-band Sentinel-1 SAR-based flood inundation study exhibited that the flood inundated a large portion $\left(6.24 \%\right.$; 40,929.02 $\mathrm{km}^{2}$ area) of the lower basin of IGBP from 30 June to 18 July 2020. The flood inundation substantially affected Bangladesh $\left(16,210.83 \mathrm{~km}^{2}\right.$; 9.09\% of the entire Bangladesh), followed by Assam $\left(9136.98 \mathrm{~km}^{2} ; 8.99 \%\right.$ of the state), Bihar (7682.38 km²; 6.29\%), West Bengal (6593.83 km²; 6.05\%), Jharkhand $\left(771.54 \mathrm{~km}^{2}\right.$; $0.76 \%)$, Meghalaya (270.28 $\left.\mathrm{km}^{2} ; 0.93 \%\right)$, and Tripura $\left(264.12 \mathrm{~km}^{2} ; 1.98 \%\right)$. The upper central and northern West Bengal, northern Bihar (Ganges basin), central and northeastern Assam (Brahmaputra basin) as well as western and central Bangladesh at the confluence of both the basins were significantly affected. It is to note that the severe flood occurrence in the upper catchments of the River Brahmaputra, and in the River Ganges gets accumulated in Bangladesh, and induces very devastating flood conditions in the region. In contrast, Jharkhand, Meghalaya, and Tripura observed the least flood inundation. 


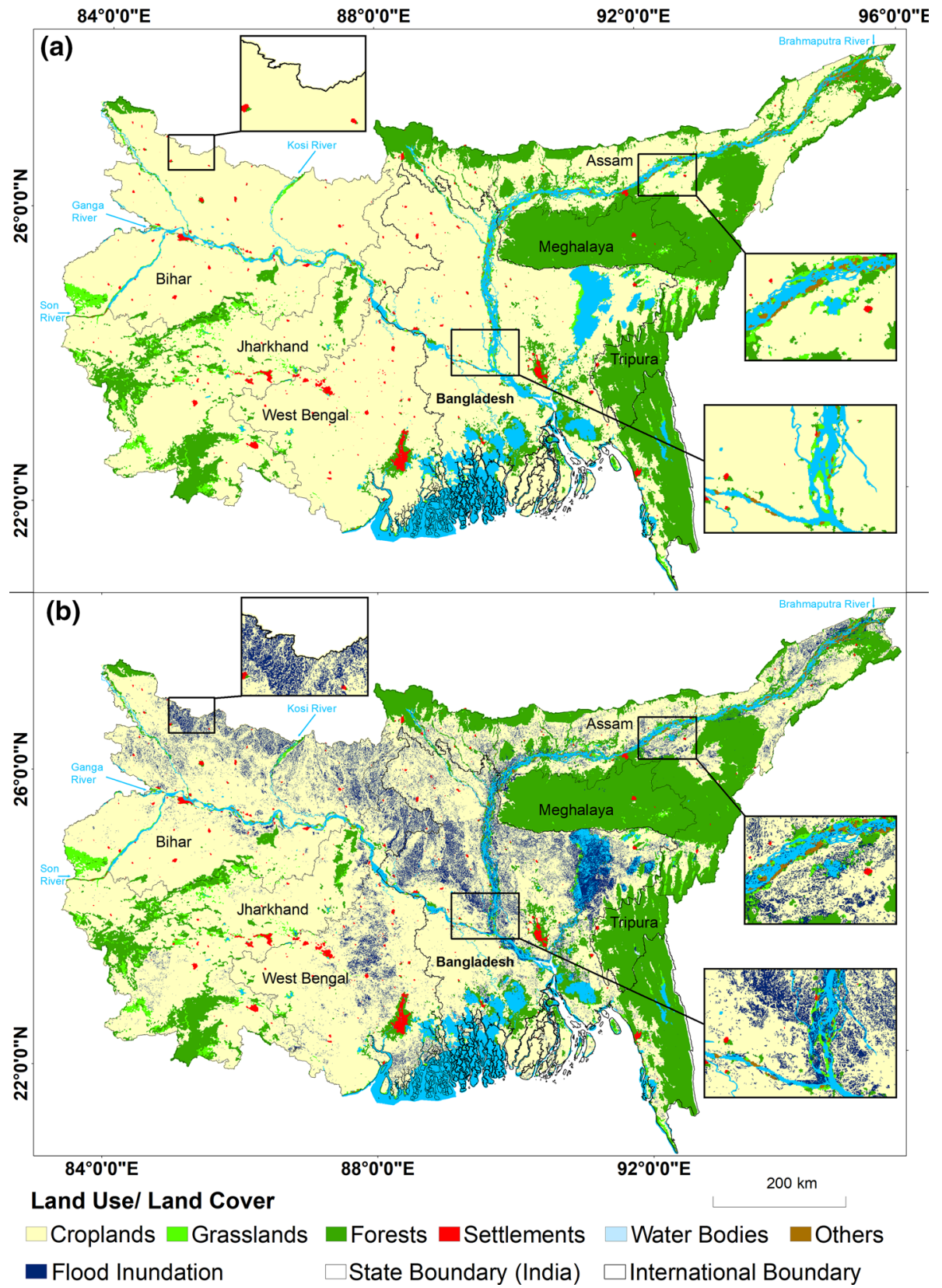

Fig. 1 a MODIS-based LULC during the pre-flood period, and $\mathbf{b}$ impact of flood inundation on LULC during peak flood period in the lower basin of IGBP (June-July 2020)

The impact of the flood was analyzed on land use/cover that exhibits a significant impact of flood inundation on cropland (4.41\% of total cropland; $19,391.42 \mathrm{~km}^{2}$ ), and built-up area $\left(20.98 \% ; 1509.91 \mathrm{~km}^{2}\right)$ during 30 June to 18 July 2020 . The recent flood 


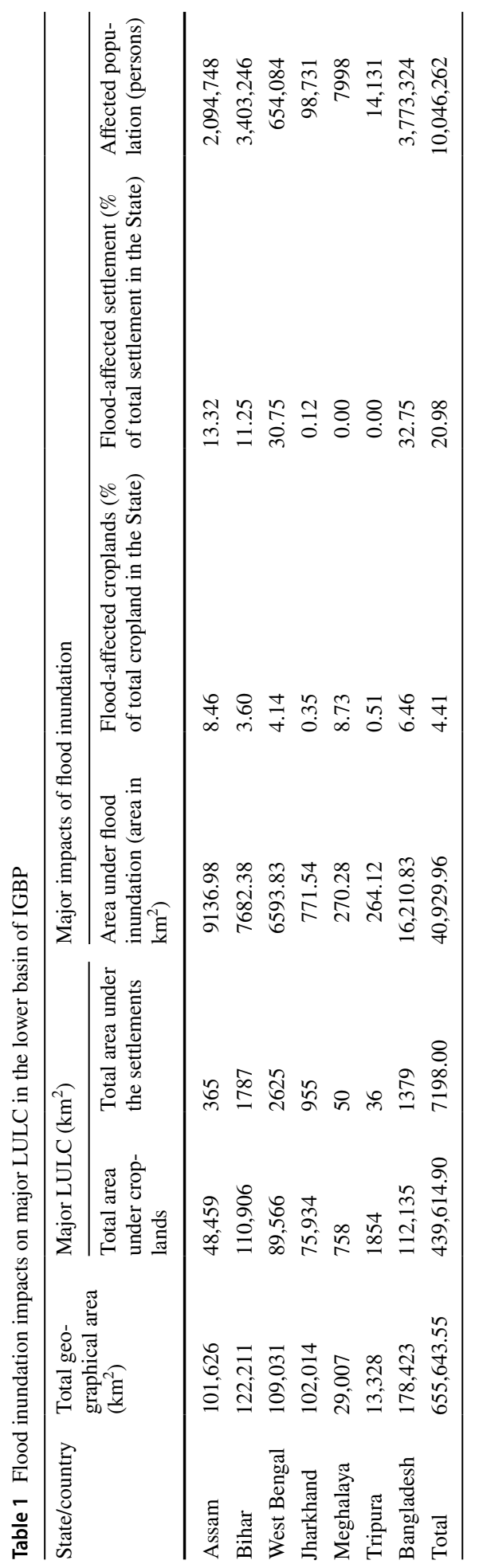


(July 2020) significantly affected the croplands in Bangladesh $\left(7242.09 \mathrm{~km}^{2} ; \sim 6.46 \%\right.$ of the total cropland of Bangladesh), followed by Assam $\left(4100.94 \mathrm{~km}^{2} ; \sim 8.46 \%\right.$ of cropland of the state), Bihar $\left(\sim 3997.17 \mathrm{~km}^{2} ; 3.60 \%\right)$, West Bengal $\left(3706.83 \mathrm{~km}^{2} ; \sim 4.14 \%\right)$, Jharkhand (268.71 km²; 0.35\%), Meghalaya $\left(66.20 \mathrm{~km}^{2} ; \sim 8.73 \%\right)$, and Tripura $\left(9.48 \mathrm{~km}^{2}\right.$, i.e., $0.51 \%)$. Similarly, flood affected settlement primarily in West Bengal $\left(807.38 \mathrm{~km}^{2}\right.$; $30.75 \%$ of settlement of WB), Bangladesh $\left(451.74 \mathrm{~km}^{2} ; 32.75 \%\right.$ of settlement of state), Bihar (201.00 km² 11.25\%), Assam (48.66 km²; 13.32\%), and Jharkhand $\left(1.13 \mathrm{~km}^{2}\right.$; $0.12 \%)$. In contrast, flood inundation has the least impact on the settlement in Meghalaya and Tripura due to its safer site and situation. The GHSL (2015)-based population exhibits that the flood affected a very large population $(\sim 10,046,262$ people) in the region, primarily in Bangladesh (37.56\% of the total marooned population), followed by Bihar (33.87\%), Assam (20.85\%), whereas the population in West Bengal (6.51\%), Jharkhand (0.98\%), Tripura (0.14\%), and Meghalaya (0.07\%) were comparatively less affected due to the flood. The effective efforts of managing disasters are being debilitated due to the recent situation of COVID-19 pandemic globally (Ishiwatari et al. 2020; Lal et al. 2020). Shifting a vast population in relief camps during flooding conditions and maintaining social and physical distance to contain the spread of COVID-19, were the major challenges (Fig. 1; Table 1).

\section{Conclusion}

The study reported the recent flood inundation (July 2020) in the lower basin IGBP that led to the inundation of an extensive area $\left(\sim 40,929.96 \mathrm{~km}^{2}\right)$ and affected an enormous population (10,046,262 persons) with worst in Bangladesh (39.61\% of the total inundation; $37.55 \%$ of the total marooned population), followed by Assam (22.32\% inundation; $20.85 \%$ of the marooned population) and Bihar (18.77\% of inundation; $33.87 \%$ of the marooned population). The flood severely affected $4.41 \%\left(19,391.42 \mathrm{~km}^{2}\right)$ of total cropland and $20.98 \%\left(1509.91 \mathrm{~km}^{2}\right)$ of settlements in the region. The concurrent flood study necessitates adopting an integrated, multi-hazard, multi-stakeholder, approach with an emphasis on disaster risk mitigation, preparedness, streamlining of the relief distribution system, with emphasis on self-reliance of the community for sustenance with local resources and practices.

Acknowledgements The authors are very thankful to the Editor for providing detailed comments that lead to a constructive improvement in the manuscript. Also, authors are thankful to the ESA Copernicus hub for archiving the Sentinel 1A/B, NASA for MODIS LULC and European commission for GHSL population data in Google Earth Engine for hassle-free cloud data processing.

Author contributions PL helped in conceptualization; software; data curation; writing-original draft; AP: contributed to software; writing —original draft; AK: helped in conceptualization; writing—reviewing and editing; project supervision.

Funding Research work is not funded by an organization.

Availability of data and material Data can be made available through user request.

Code availability GEE Code can be made available through user request. 


\section{Compliance with ethical standards}

Conflict of interest Authors declare no financial and competing interests.

\section{References}

CWC (2020) Daily flood situation report cum advisories. New Delhi

Dimri AP, Allen S (2020) Editorial: Himalayan Climate Interaction. Front Environ Sci 8:96. https://doi. org/10.3389/fenvs.2020.00096

Ishiwatari M, Koike T, Hiroki K et al (2020) Managing disasters amid COVID-19 pandemic: approaches of response to flood disasters. Prog Disaster Sci 6:100096. https://doi.org/10.1016/j.pdisas.2020.100096

Kale VS (2003) Geomorphic effects of monsoon floods on Indian rivers. In: Mirza MMQ, Dixit A, Nishat A (eds) Flood problem and management in South Asia. Springer, Dordrecht, pp 65-84

Lal P, Kumar A, Kumar S et al (2020) The dark cloud with a silver lining: assessing the impact of the SARS COVID-19 pandemic on the global environment. Sci Total Environ 732:139297. https://doi. org/10.1016/j.scitotenv.2020.139297

Milly PCD, Wetherald RT, Dunne KA, Delworth TL (2002) Increasing risk of great floods in a changing climate. Nature 415:514-517. https://doi.org/10.1038/415514a

Mohanty MP, Mudgil S, Karmakar S (2020) Flood management in India: a focussed review on the current status and future challenges. Int J Disaster Risk Reduct 49:101660. https://doi.org/10.1016/j.ijdrr .2020 .101660

Mullan D, Matthews T, Vandaele K et al (2019) Climate impacts on soil erosion and muddy flooding at 1.5 versus $2^{\circ} \mathrm{C}$ warming. Land Degrad Dev 30:94-108. https://doi.org/10.1002/ldr.3214

Nagar A (2018) How much do floods cost India? India. https://bit.ly/3hcXwua

Tanoue M, Hirabayashi Y, Ikeuchi H (2016) Global-scale river flood vulnerability in the last 50 years. Sci Rep 6:36021. https://doi.org/10.1038/srep36021

Publisher's Note Springer Nature remains neutral with regard to jurisdictional claims in published maps and institutional affiliations. 